\section{Ten-year trends in prevalence of asthma in adults in southern Brazil: comparison of two population-based studies}

\author{
Dez anos de evolução da prevalência de asma \\ em adultos, no Sul do Brasil: comparação de dois \\ estudos de base populacional
}

\author{
1 Programa de Pós-graduação \\ em Epidemiologia, \\ Universidade Federal de \\ Pelotas, Pelotas, Brasil. \\ 2 Faculdade de Medicina, \\ Universidade Federal de \\ Pelotas, Pelotas, Brasil. \\ Correspondence \\ N. S. Fiori \\ Programa de Pós-graduação \\ em Epidemiologia, \\ Universidade Federal de \\ Pelotas. \\ Rua Marechal Deodoro 1160 , \\ 3 o piso, Pelotas, RS \\ 96020-220, Brasil. \\ nsfiori@yahoo.com.br
}

\begin{abstract}
There are discrepancies in the literature regarding time trends in the occurrence of asthma in adults. This study compared asthma prevalence in two cross-sectional studies with a ten-year interval in Pelotas, Rio Grande do Sul State, Brazil. The first, in 2000, included 1,968 individuals, and the second, in 2010, 2,466 adults (20-69 years). Prevalence of wheezing and shortness of breath in the prior 12 months remained the same after ten years (6\% and $6.1 \%$, respectively). In both studies, asthma was more frequent among females and people with low family income. Physician-diagnosed asthma increased by $35.6 \%$, and lifetime incidence of asthma, by $32.2 \%$. There was no percentage change in current asthma symptoms or current asthma. Local socioeconomic improvement between the two studies was consistent with the increase in medical diagnosis, but did not reflect better management of asthma symptoms, underlining the need for investment regarding other determinants of the disease.
\end{abstract}

Asthma; Adult; Prevalence; Cross-Sectional Studies

\author{
Nadia Spada Fiori 1 \\ Helen Gonçalves 1,2 \\ Samuel C. Dumith 1 \\ Maria Aurora Dropa Chrestani Cesar 1,2 \\ Ana M. B. Menezes 1,2 \\ Silvia Elaine Cardozo Macedo 1,2
}

\section{Introduction}

Asthma affects about 300 million individuals worldwide, and some 250,000 die as a result of it 1 . The asthma burden, when measured in disability-adjusted life years lost, represents $1 \%$ of total world disease burden, and costs an estimated $€ 15$ million per year 2 . The social and individual impact of this disease is also reflected in absenteeism at work and at school, and in diminished quality of life of the ill and their relatives 1,3. According to the Pan American Health Organization (PAHO) 4, asthma affects around 15 million in Brazil and is responsible for about 350,000 hospital admissions a year (Departamento de Informática do SUS. Informações de saúde. http:// www.datasus.gov.br).

In recent decades, it has been considered one of the world's most common non-communicable chronic diseases, although its prevalence is reported in the literature as varying considerably in the general population ( $1 \%$ to $18 \%)^{1}$. That variation probably results from the use of different diagnostic criteria and from geographical and climatic differences among countries 1,5.

Despite its magnitude, there are few studies of the prevalence of asthma in adults, particularly in low- and middle-income countries. Studies in high-income countries, up to the 1990s, described asthma affecting increasing proportions of the adult population ( $\geq 20$ years old) $6,7,8,9$. For 
that age group, recent epidemiological studies have recorded a decline in the prevalence of asthma in Eastern Europe and in North America 1, while others suggest there has merely been stabilization in those regions 10,11 . In the second millennium, asthma symptoms have declined in the adult population of high-income countries 10,11, but no conclusive data are available for low- and middle-income countries 2 .

Estimates of how the prevalence of the disease is evolving in adults are made by comparing among studies or by using approximations based on other records, such as data for hospital admissions for diseases of the respiratory system.

One of the few published population-based studies to investigate this disease in adults in Brazil was conducted 10 years ago in Pelotas, a medium-sized town in Rio Grande do Sul State. In this city, the prevalence of asthma symptoms was $6 \%$ in 200012 . That same year, 43 in 100,000 adults were hospitalized for asthma. In 2009, the rate had decreased to 7 (Departamento de Informática do SUS. Informações de saúde. http://www. datasus.gov.br). In view of the available data, it can be asked, for example, whether the reduction in morbidity from asthma has been accompanied by a reduction in its prevalence.

Know the prevalence of asthma and its evolution over the years is important for health service planning, and can serve as a tool in evaluating measures introduced in the local's health systems. This article compares the prevalence of asthma in adults in Pelotas over a 10-year interval.

\section{Methodology}

This study analyzes the prevalence of asthma as compared with the study conducted by Macedo et al. 12 in 2000 as part of a broader project titled Sistema de Base Populacional para Monitoração da Prevalência e Fatores de Risco para Doenças Crônico-Degenerativas (DCG) entre Adultos de Pelotas, RS [Population-based Monitoring System for Prevalence of Chronic-degenerative Disease Risk Factors among Adults in Pelotas, Rio Grande do Sul State].

Both studies were conducted in the municipality of Pelotas, which - with a population of about 345,000 - is considered the third most populous city in the state (Instituto Brasileiro de Geografia e Estatística. Censo Demográfico 2000. http://www.ibge.gov.br). The two studies were population-based, cross-sectional, and occurred in months with similar climatic conditions (Summer and Autumn). In 1999-2000 the interviews took place from December 1999 to April 2000, and in 2010, from January to May. In both studies, sampling was by a two-stage systematic probability strategy, but in 1999-2000 more domiciles were chosen in fewer census tracts. There were then 258 urban tracts, 40 of which were selected, and the residents at 30 domiciles in each tract were interviewed. Ten years later the town had grown, and the Brazilian Institute of Geography and Statistics (Instituto Brasileiro de Geografia e Estatística. Censo Demográfico 2000. http:// www.ibge.gov.br) specified 404 urban tracts, 130 of which were selected, and 10 domiciles in each tract were visited.

All 20 to 69 year old residents of the selected domiciles were considered eligible, although the present study excluded individuals who were institutionalized or had some kind of mental and/ or physical disability.

The samples were calculated in the same fashion in both studies. Asthma was determined on the basis of $5 \%$ prevalence, one percentage point acceptable error, and 95\% confidence interval. Ten percent was added for losses and refusals, which resulted in a sample of 2,004 individuals. This study also took account of a sample design effect estimated at 1.5. For studying the associations, the sample size obtained for calculating the prevalences permitted a prevalence ratio of 1.5, for exposure odds of one, assuming $80 \%$ power and $95 \%$ confidence interval.

In both studies the interviews were conducted at participants' domiciles; in the first, however, using printed questionnaires, while in the second, small portable computers - Palm Tungsten TX PDAs. Interviewers were specially recruited and trained from among, in 2000, medical students from Pelotas Federal University (Universidade Federal de Pelotas - UFPel) and, in 2010, women at least 18 years old who had completed high school. In both studies, weights and heights were measured and not self-reported, for which purpose specific groups were trained and standardized, and then periodically underwent further standardization until field work was completed. The quality of the information collected was verified by the supervisors of both studies by reapplying a simplified questionnaire to $10 \%$ of the participants.

The questionnaire used in the 2000 study 12 comprised 110 questions, with the questions on asthma placed at the start and in the middle of the questionnaire. With very minor local adaptations, the questions were based on the instruments of the International Study of Asthma and Allergies in Childhood (ISAAC) and the European Community Respiratory Health Survey II (ECRHS II), used previously by studies in several countries. The ISAAC questionnaire has been validated in Brazil for ages from 6 to 7 years and 13 
to 14 years, and the ECRHS II 5,13, although not validated in Brazil, has been replicated in several studies of 20 to 44 year old adults. Except for one question, which was adapted, the others used in the present study were identical to those of the 2000 questionnaire. The question of "Nos últimos 12 meses, o Sr(a). teve essa crise de falta de ar? Se sim, quantas vezes?" [Have you had this attack of shortness of breath at any time in the last 12 months? If yes, how many times?] was reformulated to "Nos últimos 12 meses, quantas crises de falta de ar o(a) Sr(a). teve?" (How many attacks of shortness of breath have you had in the last 12 months?).

The independent variables collected in both studies were: sex (male and female); age (in complete years); self-reported skin color by IBGE categories (white, black, brown, yellow and indigenous); family income in the past month (in minimum wages - MW); tobacco use (non-smoker, smoker, and former smoker); body mass index (BMI) 14 calculated from the height and weight measurements.

The dependent variables were replicated from Macedo et al. 12 and described different diagnoses of asthma: cumulative asthma (self-report of lifetime asthma); medical diagnosis (self-report of asthma diagnosed by a physician in lifetime); current asthma (self-reported asthma in the last 12 months); current symptoms (self-report of simultaneous episodes of dyspnea and whistling in the past 12 months).

The two studies used the variable "current asthma symptoms" in order to examine the association between asthma and the independent variables. The dataset of the 2000 study was re-examined to permit new analyses in line to the hierarchical model proposed in 2010. In the descriptive analysis, the data were presented in terms of prevalence and $95 \%$ confidence interval (95\%CI). Poisson regression was used for the crude and adjusted analyses (in 2010, considering the design effect). The adjusted analysis was conducted at two levels of causality: at the first level, including demographic variables and economic status and, at the second, tobacco use and BMI. Data were analyzed using Stata 10.0 (Stata Corp., College Station, USA), with a $5 \%$ level of significance for two-tailed tests.

The study was approved by the research ethics committee of the school of medicine at UFPel, and the interviews were conducted with the participants' consent.

\section{Results}

In 2000, 1968 people from 20 to 69 years old were interviewed and, in the present study, 2466. Both studies visited about 1200 domiciles. The losses and refusals were $10.7 \%$ in 2010 , and slightly higher among men than among women $(5.8 \%$ and $4.2 \%$, respectively). In the study by Macedo et al. 12 the rate was $9.6 \%$.

Table 1 describes the study populations in terms of demographic characteristics, economic class, tobacco use and BMI. In both 2000 and 2010, a majority of participants were women, white-skinned, non-smokers, with BMI of $25 \mathrm{~kg} /$ $\mathrm{m}^{2}$ or higher, and family income from 1.01 to 3.0 MWs. The sample distributions were also similar, the main differences between them being the higher proportion of smokers in 2000 (30.5\% vs. $22.9 \%$ in 2010), of people with family income of less than one MW (30.7\% in 2000; $12.3 \%$ in 2010), and with higher than normal BMI in 2010 (53.1\% in 2000; 61\% in 2010).

Figure 1 shows the prevalences of the diagnostic criteria in both studies. In 2010, there was a $32.2 \%$ increase in the prevalence of lifetime asthma (14.3\% in 2000; $18.9 \%$ in 2010) and $35.6 \%$ in medical diagnosis $(12.9 \%$ in $2000 ; 17.5 \%$ in 2010), as compared with the 2000 study (both with $\mathrm{p}<0.001)$. However, no difference was returned by the criteria for current asthma ( $4.2 \%$ in $2000 ; 5.2 \%$ in 2010$)$ or in asthma symptoms $(6 \%$ in 2000; $6.1 \%$ in 2010).

Prevalence of current asthma symptoms in the present study was $6.1 \%$ (95\%CI: 5.1-7.0), very close to the finding of the previous study $(6 \%$; 95\%CI: 5.0-7.1). Table 2 shows the distribution of the prevalence of current asthma symptoms by demographic and behavioral factors and economic level in the two studies. It is clear that, 10 years later, the prevalence of asthma symptoms continues greater in the female sex, in people of non-white skin color and with family income of less than one MW. However, there are divergences in the prevalence of asthma by age range: in 2000 , it was greater among the 60 to 69 year olds (10.1\%), and had diminished by $56 \%$ in this age group by 2010 (4.4\%), when prevalence was highest $(7 \%)$ in 50 to 59 year old age group.

Another important difference encountered in the present study was the higher prevalence of asthma symptoms among the obese (8.9\%) and smokers $(9.7 \%)$. In the previous study, the rates were $14.3 \%$ in people with a BMI deficit and $8.1 \%$ in former smokers, a proportion 1.5 times higher than found in 2010. The prevalence of current asthma symptoms increased among young adults (20 to 49 years old) and people with medium family income (3.01 to 6.0 MWs), and 
Demographic, socioeconomic, behavioral and anthropometric characteristics of the populations studied, by study year. Pelotas, Rio Grande do Sul State, Brazil.

\begin{tabular}{|c|c|c|c|c|c|c|}
\hline \multirow[t]{2}{*}{ Variable } & \multicolumn{3}{|c|}{ Year $2000(N=1,968)$} & \multicolumn{3}{|c|}{ Year $2010(N=2,466)$} \\
\hline & $\mathbf{n}$ & $\%$ & $95 \% \mathrm{Cl}$ & $\mathbf{n}$ & $\%$ & $95 \% \mathrm{Cl}$ \\
\hline \multicolumn{7}{|l|}{ Sex } \\
\hline Male & 846 & 43.0 & $40.8-45.2$ & 1,065 & 43.2 & $41.2-45.1$ \\
\hline Female & 1,122 & 57.0 & $54.8-59.2$ & 1,401 & 56.8 & $54.8-58.8$ \\
\hline \multicolumn{7}{|l|}{ Skin color * } \\
\hline White & 1,636 & 83.1 & 81.5-84.8 & 1,918 & 77.9 & $76.2-79.5$ \\
\hline Non-white & 332 & 16.9 & $15.2-18.5$ & 545 & 22.1 & $20.5-23.8$ \\
\hline \multicolumn{7}{|l|}{ Age (years) * } \\
\hline $20-29$ & 461 & 23.4 & $21.6-25.3$ & 595 & 24.1 & $22.4-25.8$ \\
\hline $30-39$ & 460 & 23.4 & $21.5-25.3$ & 462 & 18.7 & $17.2-20.3$ \\
\hline $40-49$ & 441 & 22.4 & $20.6-24.3$ & 545 & 22.1 & 20.5-23.7 \\
\hline $50-59$ & 377 & 19.2 & 17.4-20.9 & 495 & 20.1 & $18.5-21.6$ \\
\hline $60-69$ & 228 & 11.6 & 10.2-13.0 & 369 & 15.0 & $13.5-16.4$ \\
\hline \multicolumn{7}{|c|}{ Family income (MW) * } \\
\hline$\leq 1.0$ & 600 & 30.7 & $28.7-32.8$ & 299 & 12.3 & 10.9-13.5 \\
\hline $1.01-3.0$ & 819 & 41.9 & 39.7-44.1 & 999 & 40.9 & $39.0-42.9$ \\
\hline $3.01-6.0$ & 297 & 15.2 & 13.6-16.8 & 703 & 28.8 & $27.0-30.6$ \\
\hline$\geq 6.01$ & 237 & 12.2 & 10.7-13.6 & 439 & 18.0 & $16.5-19.5$ \\
\hline \multicolumn{7}{|l|}{ Tobacco use } \\
\hline Non-smoker & 946 & 48.1 & $45.8-50.3$ & 1,323 & 53.6 & $51.7-55.6$ \\
\hline Former smoker & 422 & 21.4 & 19.6-23.2 & 579 & 23.5 & $21.2-24.5$ \\
\hline Current smoker & 600 & 30.5 & 28.4-32.5 & 564 & 22.9 & $21.8-25.1$ \\
\hline \multicolumn{7}{|l|}{$\mathrm{BMI}$ * } \\
\hline Underweight & 56 & 2.9 & $2.1-3.6$ & 28 & 1.2 & $0.8-1.7$ \\
\hline Eutrophic & 852 & 44.0 & 41.8-46.2 & 841 & 37.9 & $35.9-39.9$ \\
\hline Overweight & 652 & 33.7 & 31.6-35.8 & 789 & 35.6 & $33.6-37.5$ \\
\hline Obese & 375 & 19.4 & $17.6-21.1$ & 561 & 25.2 & $23.5-27.1$ \\
\hline
\end{tabular}

BMI: body mass index; MW: minimum wage.

* Maximum value ignored: 247.

decreased about $35 \%$ among former smokers. In 2010, prevalence of asthma symptoms among obese women smokers was $22.2 \%$, and the likelihood of their having asthma symptoms was 8.3 times greater than for non-smoking, non-obese men (95\%CI: 3.1-22.3).

Table 3 shows the crude and adjusted analysis of the association, in both studies, between asthma symptoms and demographic, behavioral and anthropometric factors, and economic status. In 2000, a crude association was found between current asthma symptoms and female sex, age from 60 to 69 years old, white skin color, low family income, tobacco use, and low BMI. In that same study, although skin color and BMI lost statistical significance after adjusted analysis, a higher prevalence ratio (PR) persisted for asthma symptoms in individuals with low BMI $\left(<18.5 \mathrm{~kg} / \mathrm{m}^{2}\right)$.
10 years later, the bivariate and adjusted analyses were in agreement on the association between asthma symptoms and female sex, low family income, current tobacco use, and obesity.

\section{Discussion}

In comparing with the results found 10 years ago for the prevalence of asthma and its association with risk factors, using identical methodology and diagnostic criteria, the present study highlights three key results. Firstly, medical diagnoses of asthma increased by $35.6 \%$, and the prevalence of lifetime asma, by $32.2 \%$, both statistically significant increases $(\mathrm{p}<0.001)$.

The second important result was there being no percentage variation in the other two diag- 


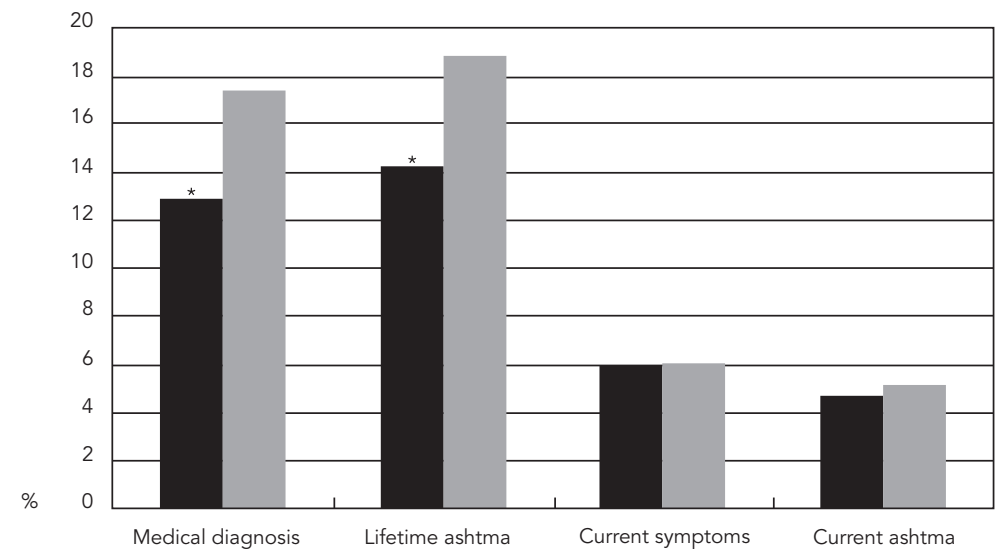

Diagnostic criteria

${ }^{*} p<0.001$

nostic criteria used: current asthma symptoms (6.1\%) and current asthma (5.2\%).

The third finding shows that female sex continued associated with current asthma symptoms ( $\mathrm{PR}=1.71$; 95\%CI: $1.22-2.40$ ), while the associations with tobacco use $(\mathrm{PR}=2.05 ; 95 \% \mathrm{CI}$ : 1.43-2.95) and obesity ( $\mathrm{PR}=1.80$; 95\%CI: 1.24 2.62) have become significant. In 2000 , there was association with former smokers and low BMI.

The increase in medical diagnosis of asthma and in the prevalence of lifetime asthma have been described in other studies 7,8,9,15,16. For example, surveys conducted in the United Kingdom in three different years (1990, 1992 and 1998) detected increases in the prevalence of lifetime asthma (16\%, 20\% and $21 \%$, respectively) and asthma diagnosed by a physician $(12 \%, 17 \%$ and $18 \%$, respectively) 9 . Some authors suggest that these differences result from the population's increased knowledge of the symptoms of asthma, and from increased availability of physicians to make the diagnosis 7, rather than from the disease's increased prevalence.

The differences found in the current study in the prevalence of medical diagnosis and of lifetime asthma may be related to substantial changes in the local population. Over the past seven years, according to population studies performed in the city, there was an improvement in economic status of the population, with migration from economic classes D and E to class $\mathrm{C} 17$. This economic improvement may permit greater access to health information and services, as has occurred elsewhere. The population studied may, thus, have received more diagnoses and information about the disease, which would account for the increase in self-reported lifetime asthma.

One salient result in 2010, was that the occurrence of asthma symptoms had not diminished despite improvement in important determinant factors, such as socioeconomic status and tobacco use in the city. Socioeconomic development can bring families to learn more about the disease and its management, in addition to enabling them to afford treatment. Also, gradual reduction of exposure to the toxic components of tobacco smoke would be expected to reduce the occurrence of asthma. These two factors jointly have a positive influence in reducing attacks of wheezing and shortness of breath. However, it is possible that variations in the prevalence of atopy and environmental pollution (which were not evaluated in this study), together with increasing overweight/obesity, may have offset the reduction in symptoms that might be expected to result from reduced tobacco use and socioeconomic improvement 18,19,20.

The literature already shows that prevalence of asma among adults was increasing up to the 1990s and that, after that period, it stabilized or diminished. Nonetheless, the few studies in low-income countries, such as on the African continent, still show increasing prevalence of asthma among adults 1 . Accordingly, the discovery that the prevalence of asthma symptoms has stabilized among the over 20 year olds in 
Distribution of prevalence of current asthma symptoms, by characteristics studied, by study year. Pelotas, Rio Grande do Sul State, Brazil.

\begin{tabular}{|c|c|c|c|c|c|}
\hline \multirow[t]{2}{*}{ Variables } & \multicolumn{2}{|c|}{ Year $2000(N=1,968)$} & \multicolumn{2}{|c|}{ Year $2010(N=2,466)$} & \multirow[t]{2}{*}{ Percentage change } \\
\hline & $\%$ & $95 \% \mathrm{Cl}$ & $\%$ & $95 \% \mathrm{Cl}$ & \\
\hline \multicolumn{6}{|l|}{ Sex } \\
\hline Male & 4.7 & $3.3-6.1$ & 4.3 & $3.1-5.6$ & -8.5 \\
\hline Female & 7.0 & $5.5-8.5$ & 7.5 & $6.1-8.8$ & 7.1 \\
\hline \multicolumn{6}{|l|}{ Skin color } \\
\hline White & 5.6 & $4.5-6.7$ & 5.8 & $4.7-6.8$ & 3.6 \\
\hline Non-white & 8.4 & $5.4-11.4$ & 7.2 & $5.0-9.4$ & -14.3 \\
\hline \multicolumn{6}{|l|}{ Age (years) } \\
\hline $20-29$ & 5.0 & $3.0-7.0$ & 6.8 & $4.7-8.8$ & 36.0 \\
\hline $30-39$ & 5.2 & $3.1-7.2$ & 5.7 & $3.5-7.8$ & 9.6 \\
\hline $40-49$ & 4.3 & $2.4-6.2$ & 6.1 & $4.1-8.1$ & 41.9 \\
\hline $50-59$ & 8.0 & $5.2-10.7$ & 7.0 & $4.7-9.2$ & -12.5 \\
\hline $60-69$ & 10.1 & $6.1-14.0$ & 4.4 & $2.3-6.5$ & -56.4 \\
\hline \multicolumn{6}{|l|}{ Family income (MW) } \\
\hline$\leq 1.0$ & 8.3 & $6.1-10.5$ & 7.9 & $4.8-11.1$ & -4.8 \\
\hline $1.01-3.0$ & 5.9 & $4.2-7.5$ & 7.0 & $5.4-8.6$ & 18.6 \\
\hline $3.01-6.0$ & 3.4 & $1.3-5.4$ & 5.6 & $3.9-7.3$ & 64.7 \\
\hline$\geq 6.01$ & 4.2 & $1.6-6.8$ & 3.9 & $2.1-5.7$ & -7.1 \\
\hline \multicolumn{6}{|l|}{ Tobacco use } \\
\hline Non-smoker & 4.6 & $3.2-5.9$ & 4.9 & $3.8-6.1$ & 6.5 \\
\hline Former smoker & 8.1 & $5.4-10.7$ & 5.2 & $3.4-7.1$ & -35.8 \\
\hline Current smoker & 7.0 & $5.0-9.0$ & 9.7 & $7.2-12.1$ & 38.6 \\
\hline \multicolumn{6}{|l|}{ BMI } \\
\hline Underweight & 14.3 & $4.8-23.7$ & 7.4 & 0.0 & -48.3 \\
\hline Eutrophic & 5.1 & $3.6-6.5$ & 5.3 & $3.7-6.8$ & 4.0 \\
\hline Overweight & 5.7 & $3.9-7.5$ & 5.3 & $3.7-6.9$ & -7.0 \\
\hline Obese & 7.5 & 4.8-10.1 & 8.8 & $6.5-11.2$ & 12.0 \\
\hline Total & 6.0 & $5.0-7.1$ & 6.1 & $5.1-7.0$ & 1.6 \\
\hline
\end{tabular}

BMI: body mass index; MW: minimum wage.

Pelotas is consistent with the situation of economic growth in Brazil when compared with prevalence in wealthier countries.

The results encountered in 2010 are consistent with those of previous studies 1,6,8,18,21, $22,23,24,25$. The adjusted analysis corroborate the association between prevalence of asthma symptoms and the following factors: female sex, tobacco use, obesity and low family income.

It is believed that changes in the health system over the 10 year interval may have had a positive effect on some determinants of the occurrence of asthma. These changes include expansion of the primary care network, introduction of the Family Health Program in 2002 26, and increasing use of outpatient health care services 27 . In the past two years, primary care personnel have been given training in child asthma, and children have been provided with medications, including pressurized aerosols. Although no measures have been taken specifically for asthma in adults, more frequent contact with health services during children's treatment may have influenced management of the disease in the population studied. That is to say, the investment in combating child asthma may have had an indirect, negative effect on the prevalence of asthma symptoms among adults. Also, efforts to combat tobacco use, which is an important determinant of asthma, have been strengthened in the city and in Brazil. The reduction in the proportion of tobacco users in the local population is an encouragement to continue with efforts made in this regard to date, as one in five adults still smokes. Halving the proportion 
Crude and adjusted analysis of the association between current asthma symptoms and demographic, socioeconomic, behavioral and anthropometric characteristics of the populations studied, by study year. Pelotas, Rio Grande do Sul State, Brazil.

\begin{tabular}{|c|c|c|c|c|c|c|c|c|c|c|c|c|}
\hline \multirow[t]{3}{*}{ Variable } & \multicolumn{6}{|c|}{ Year $2000(N=1,968)$} & \multicolumn{6}{|c|}{ Year $2010(N=2,466)$} \\
\hline & \multicolumn{3}{|c|}{ Crude analysis } & \multicolumn{3}{|c|}{ Adjusted analysis } & \multicolumn{3}{|c|}{ Crude analysis } & \multicolumn{3}{|c|}{ Adjusted analysis } \\
\hline & PR & $95 \% \mathrm{Cl}$ & $p$-value & PR & $95 \% \mathrm{Cl}$ & $p$-value & PR & $95 \% \mathrm{Cl}$ & $p$-value & PR & $95 \% \mathrm{Cl}$ & $p$-value \\
\hline Sex & & & 0.03 * & & & $0.05 *$ & & & 0.002 * & & & 0.002 * \\
\hline Male & 1.00 & - & & 1.00 & - & & 1.00 & - & & 1.00 & - & \\
\hline Female & 1.50 & $1.04-2.12$ & & 1.44 & $1.01-2.05$ & & 1.71 & $1.23-2.40$ & & 1.71 & $1.22-2.40$ & \\
\hline Skin color & & & 0.04 * & & & $0.21 *$ & & & 0.20 * & & & 0.34 * \\
\hline White & 1.00 & - & & 1.00 & - & & 1.00 & - & & 1.00 & - & \\
\hline Non-white & 1.51 & $1.02-2.25$ & & 1.25 & $0.84-1.87$ & & 1.25 & $0.89-1.76$ & & 1.20 & $0.84-1.70$ & \\
\hline Age (years) & & & $0.01 \star \star$ & & & $0.01 * \star$ & & & $0.43 * \star$ & & & $0.41 \star \star$ \\
\hline $20-29$ & 1.00 & - & & 1.00 & - & & 1.00 & - & & 1.00 & - & \\
\hline $30-39$ & 1.04 & $0.59-1.86$ & & 1.00 & $0.56-1.76$ & & 0.84 & $0.48-1.46$ & & 0.83 & $0.48-1.44$ & \\
\hline $40-49$ & 0.86 & $0.47-1.60$ & & 0.85 & $0.46-1.57$ & & 0.90 & $0.53-1.54$ & & 0.92 & $0.54-1.56$ & \\
\hline $50-59$ & 1.60 & $0.90-2.81$ & & 1.55 & $0.88-2.75$ & & 1.03 & $0.63-1.68$ & & 1.04 & $0.64-1.70$ & \\
\hline $60-69$ & 2.02 & $1.13-3.60$ & & 2.06 & $1.16-3.67$ & & 0.65 & $0.35-1.20$ & & 0.64 & $0.35-1.20$ & \\
\hline Family income (MW) & & & $0.006 * *$ & & & $0.01 * \star$ & & & $0.006 * \star$ & & & $0.01 \star \star$ \\
\hline$\leq 1.0$ & 1.97 & $1.01-3.84$ & & 1.96 & $1.00-3.83$ & & 2.03 & $1.18-3.50$ & & 1.93 & $1.11-3.40$ & \\
\hline $1.01-3.0$ & 1.39 & $0.71-2.69$ & & 1.41 & $0.74-2.73$ & & 1.80 & $1.07-3.01$ & & 1.71 & $1.01-2.72$ & \\
\hline $3.01-6.0$ & 0.80 & $0.34-1.88$ & & 0.80 & $0.34-1.88$ & & 1.43 & $0.79-2.60$ & & 1.41 & $0.78-2.45$ & \\
\hline$\geq 6.01$ & 1.00 & - & & 1.00 & - & & 1.00 & - & & 1.00 & - & \\
\hline Tobacco use & & & 0.02 * & & & 0.03 * & & & $<0.001$ * & & & $<0.001$ * \\
\hline Non-smoker & 1.00 & - & & 1.00 & - & & 1.00 & - & & 1.00 & - & \\
\hline Former smoker & 1.77 & $1.15-2.73$ & & 1.67 & $1.07-2.60$ & & 1.06 & $0.70-1.61$ & & 1.20 & $0.77-1.83$ & \\
\hline Current smoker & 1.54 & $1.02-2.30$ & & 1.56 & $1.04-2.34$ & & 1.96 & $1.39-2.76$ & & 2.05 & $1.43-2.95$ & \\
\hline $\mathrm{BMI}$ & & & 0.02 * & & & 0.07 * & & & 0.01 * & & & 0.01 * \\
\hline Underweight & 2.83 & $1.40-5.70$ & & 2.44 & $1.21-4.92$ & & 1.41 & $0.36-5.56$ & & 1.23 & $0.32-4.66$ & \\
\hline Eutrophic & 1.00 & - & & 1.00 & - & & 1.00 & - & & 1.00 & - & \\
\hline Overweight & 1.12 & $0.73-1.72$ & & 1.00 & $0.65-1.56$ & & 1.00 & $0.68-1.49$ & & 1.11 & $0.75-1.65$ & \\
\hline Obese & 1.48 & $0.93-2.34$ & & 1.18 & $0.74-1.90$ & & 1.68 & $1.16-2.44$ & & 1.80 & $1.24-2.62$ & \\
\hline
\end{tabular}

BMI: body mass index; MW: minimum wage; PR: prevalence ratio.

* Wald Test for heterogeneity;

** Wald Test for linear trend.

of tobacco users in the town would potentially reduce the prevalence of asthma symptoms by $11.2 \%$ in the adult population. However, the reduction in the proportion of smokers observed after 10 years has not reduced the prevalence of asthma symptoms, suggesting that other factors, mentioned above, with an opposite influence on the disease, have increased in proportion over the same period. The literature shows that atopy, obesity and increasing environmental pollution, consistent with increasing urbanization of the town over those last 10 years, may cause an increase in prevalences of asthma 18,19,20.

Stabilization in the prevalence of asthma in this age group has also been described in other studies, as already mentioned. North American research, using data from surveys by the Centers for Disease Control and Prevention (CDC), and studies in Sweden, surmise that this trend results from increasing medical diagnosis, and thus from greater contact between asthma sufferers and health services, and consequent improved management of the disease $7,11,28$. This present study was not able to detect these changes, which will require new studies to evaluate the appropriateness of asthma management and treatment by, among other things, identifying access to medication.

Among the risk factors described in association with asthma, obesity is another modifiable 
factor deserving particular attention by health care. The increase in BMI in the population suggests a need to formulate strategies for dietary education and to foster (and provide facilities for) physical activity, given that this disease is also related to a number of other chronic non communicable diseases, such as systemic arterial hypertension, diabetes mellitus, dyslipidemias, and others 29. Concomitant obesity and smoking in women resulted in higher risk of asthma symptoms ( $\mathrm{PR}=8.3$ ) than in non-smoking, nonobese men (data not presented). That observation underscores the need to to develop health intervention and education strategies for this specific group.

Therefore, it is believed that these results are consistent with the hypothesis that the stabilization in the prevalence of asthma symptoms in adults in the last 10 years in Pelotas has resulted from the improvements described above in some conditions of the local population, which reflect nationwide changes.

Possible limitations should be noted in relation to this study. Using reported symptoms, with no pulmonary tests for diagnosing asthma, entails restrictions. There are known to be other pathologies with similar symptoms to those of asthma, such as chronic obstructive pulmonary disease (COPD). Nonetheless, in this study, the factors associated with COPD were not associated with the presence of asthma symptoms; that is, age (older adults: $\geq 60$ years) and low BMI 30 . Other restrictions on the analyses of this study relate to not including the variables "family history of asthma" and "atopy", and the possibility of reverse causality in the association between obesity and asthma symptoms. However, the appropriateness of using the criterion "wheezing with shortness of breath in the last year" to determine asthma is endorsed by the document Global Initiative for Asthma (GINA) 2. That document points to the concomitant occurrence of these two symptoms as a clinically significant indication of asthma, and "wheezing in the past
12 months" as the most important symptom for identifying individuals with asthma 2. In 2000 and in 2010 , the criteria used to determine asthma was "wheezing with shortness of breath in the last year".

One positive aspect of the study is the appropriateness of the comparison interval, with no alterations in clinical diagnosis of the disease in Brazil over that interval. Also, both studies had relatively high response rates (around 90\%), and losses did not bias this present study, because they were not related to the occurrence of the outcome. The use of the ISAAC questionnaire (validated in Brazil for children and adolescents) among adults is warranted by its widespread use in other studies and by the finding in the literature of a strong correlation between the prevalence data and ECHRS, when applied in the same country ${ }^{31}$. Also, its use in the adolescente population suggests a satisfactory degree of applicability in the adult population 12 . Note also that its use in both studies eliminates the possibility of interference in the results.

Lastly, the finding by this present study that prevalence of asthma symptoms has stabilized offers the town new information regarding this disease among adults. Given the improvements in socioeconomic factors and the reduction in smoking in the population, it is shown to be possible to reduce the prevalence of asthma symptoms. Interventions that leverage control of asthma symptoms - such as constant capacity-building for primary health personnel, distribution of drugs to adults, and some measures directed to reducing obesity - are considered to contribute positively to controlling the disease.

New studies are believed to be necessary (and are encouraged) to investigate other factors that determine the occurrence of asthma symptoms in adults, such as access to and use of medication, adhesion to treatment, and knowledge of the disease and its prevention. This information will inform measures and strategies to be developed with a view to reducing asthma. 


\section{Resumo}

Há divergências na literatura quanto às tendências temporais da ocorrência de asma em adultos. Este estudo objetivou comparar a prevalência de asma em dois levantamentos realizados com um intervalo de dez anos, em Pelotas, Rio Grande do Sul, Brasil. Os dois estudos foram transversais, de base populacional e com estratégias semelhantes de amostragem. O primeiro, feito em 2000, incluiu 1.968 indivíduos, e o segundo, em 2010, 2.466 adultos (20-69 anos). A prevalência de chiado e falta de ar, nos últimos 12 meses, manteve-se estável após dez anos (6\% e 6,1\%, respectivamente). Em ambos os estudos, a prevalência de asma foi maior em mulheres e pessoas com renda familiar baixa. Houve aumento de 35,6\% no diagnóstico médico de asma e de $32,2 \%$ na prevalência de asma na vida. Não houve variação percentual para sintomas atuais de asma e asma atual. A melhora socioeconômica local, observada entre os estudos, foi coerente com o aumento do diagnóstico medico, porém não refletiu um melhor manejo dos sintomas da asma, o que reforça a necessidade de investimentos em outros determinantes da doença.

Asma; Adulto; Prevalência; Estudos Transversais

\section{Contributors}

N. S. Fiori participated in conception of the project, analysis and interpretation of the data, drafting the article and substantial critical review of its intellectual content, and final approval of the manuscript. A. M. B. Menezes collaborated in conception of the project, data interpretation, substantial critical review of intellectual content, and final approval of the manuscript. H. Gonçalves, S. C. Dumith and M. A. D. C. Cesar contributed to conception of the project, data analysis and interpretation, substantial critical review of intellectual content, and final approval of the manuscript. S. E. C. Macedo participated in data interpretation, substantial critical review of intellectual content, and final approval of the manuscript.

\section{References}

1. Bateman ED, Hurd SS, Barnes PJ, Bousquet J, Drazen JM, FitzGerald M, et al. Global strategy for asthma management and prevention: GINA executive summary. Eur Res J 2008; 31:143-78.

2. Masoli M, Fabian D, Holt S, Beasley R; Global Initiative for Asthma (GINA) Program. The global burden of asthma: executive summary of the GINA Dissemination Committee report. Allergy 2004; 59:469-78.

3. Ampon RD, Williamson M, Correll PK, Marks GB. Impact of asthma on self-reported health status and quality of life: a population based study of Australians aged 18-64. Thorax 2005; 60:735-9.
4. Organização Pan-Americana da Saúde. Prevenção e controle de doenças: doenças respiratórias crônicas. http://www.opas.org.br/prevencao/mos_info. cfm?codigodest=226 (accessed on 10/Nov/2009).

5. Variations in the prevalence of respiratory symptoms, self-reported asthma attacks, and use of asthma medication in the European Community Respiratory Health Survey (ECRHS). Eur Resp J 1996; 9:687-95.

6. Moorman JE, Rudd RA, Johnson CA, King M, Minor P, Bailey C, et al. National surveillance for asthma: United States, 1980-2004. MMWR Surveill Summ 2007; 56:1-54. 
7. Barraclough R, Devereux G, Hendrick DJ, Stenton SC. Apparent but not real increase in asthma prevalence during the 1990s. Eur Respir J 2002; 20: 826-33.

8. Brogger J, Bakke P, Eide GE, Johansen B, Andersen A, Gulsvik A. Long-term changes in adult asthma prevalence. Eur Respir J 2003; 21:468-72.

9. Woods RK, Walters EH, Wharton C, Watson N, Abramson $\mathrm{M}$. The rising prevalence of asthma in young Melbourne adults is associated with improvement in treatment. Ann Allergy Asthma Immunol 2001; 87:117-23.

10. Verlato G, Corsico A, Villani S, Cerveri I, Migliore E, Accordini S, et al. Is the prevalence of adult asthma and allergic rhinitis still increasing? Results of an Italian study. J Allergy Clin Immunol 2003; 111:1232-8

11. Lötvall J, Ekerljung L, Rönmark EP, Wennergren G, Lindén A, Rönmark E, et al. West Sweden Asthma Study: prevalence trends over the last 18 years argues no recent increase in asthma. Respir Res 2009; 10:94.

12. Macedo SEC, Menezes AMB, Knorst M, Dias-daCosta JS, Gigante DP, Olinto MT, et al. Fatores de risco para a asma em adultos, Pelotas, Rio Grande do Sul, Brasil. Cad Saúde Pública 2007; 23:863-74.

13. Solé D, Vanna AT, Yamada E, Rizzo MC, Naspitz CK. International Study of Asthma and Allergies in Childhood (ISAAC) written questionnaire: validation of the asthma component among Brazilian children. J Investig Allergol Clin Immunol 1998; 8:376-82.

14. World Health Organization. Global database on body mass index: an interactive surveillance tool for monitoring nutrition transition. http:// apps.who.int/bmi/index.jsp (accessed on 02/ Sep/2010)

15. Urrutia I, Aguirre U, Sunyer J, Plana E, Muniozguren N, Martínez-Moratalla J, et al. Changes in the prevalence of asthma in the Spanish cohort of the European Community Respiratory Health Survey (ECRHS-II). Arch Bronconeumol 2007; 43:425-30.

16. Simpson CR, Sheikh A. Trends in the epidemiology of asthma in England: a national study of 333,294 patients. J R Soc Med 2010; 103:98-106.

17. Associação Nacional de Empresas de Pesquisa. Critério de classificação econômica Brasil. http:// www.datavale-sp.com.br/CCEB.pdf (accessed on 01/Oct/2010).

18. Chen Y, Bishop M, Liepold H. Increased effect of obesity on asthma in adults with low household income. J Asthma 2010; 47:263-8.

19. Sakar A, Yorgancioglu A, Dinc G, Yuksel H, Celik P, Dagyildizi L, et al. The prevalence of asthma and allergic symptoms in Manisa, Turkey (a western city from a country bridging Asia and Europe). Asian Pac J Allergy Immunol 2006; 24:17-25.
20. Viinanen A, Munhbayarlah S, Zevgee T, Narantsetseg L, Naidansuren T, Koskenvuo M, et al. Prevalence of asthma, allergic rhinoconjunctivitis and allergic sensitization in Mongolia. Allergy 2005; 60:1370-7.

21. Gwynn RC. Risk factors for asthma in US adults: results from the 2000 Behavioral Risk Factor Surveillance System. J Asthma 2004; 41:91-8.

22. McHugh MK, Symanski E, Pompeii LA, Delclos GL. Prevalence of asthma among adult females and males in the United States: results from the $\mathrm{Na}$ tional Health and Nutrition Examination Survey (NHANES), 2001-2004. J Asthma 2009; 46:759-66.

23. Ellison-Loschmann L, Sunyer J, Plana E, Pearce N, Zock JP, Jarvis D, et al. Socioeconomic status, asthma and chronic bronchitis in a large communitybased study. Eur Respir J 2007; 29:897-905.

24. Barros MBA, César CLG, Carandina L, Torre GD. Desigualdades sociais na prevalência de doenças crônicas no Brasil, PNAD-2003. Ciênc Saúde Coletiva 2006; 11:911-26.

25. Theme-Filha MM, Szwarcwald CL, Souza-Junior PRB. Socio-demographic characteristics, treatment coverage, and self-rated health of individuals who reported six chronic diseases in Brazil, 2003. Cad Saúde Pública 2005; 21 Suppl 1:S43-53.

26. Secretaria Municipal de Saúde de Pelotas. Plano Municipal de Saúde, 2007-2009. Pelotas: Secretaria Municipal de Saúde de Pelotas; 2007.

27. Nader GA. Aumento na utilização de consultas ambulatoriais nos últimos 15 anos: comparação de dois estudos de base populacional [Masters thesis]. Pelotas: Programa de Pós-graduação em Epidemiologia, Universidade Federal de Pelotas; 2007.

28. American Lung Association. Trends in asthma morbidity and mortality. http://www.lungusa.org/ finding-cures/our-research/trend-reports/asth ma-trend-report.pdf (accessed on 18/Sep/2010)

29. Malta DC, Cezário AC, Moura L, Morais Neto OL, Silva Junior JB. A construção da vigilância e prevenção das doenças crônicas não transmissíveis no contexto do Sistema Único de Saúde. Epidemiol Serv Saúde 2006; 15:47-65.

30. Menezes AMB, Jardim JR, Pérez-Padilla R, Camelier A, Rosa F, Nascimento O, et al. Prevalence of chronic obstructive pulmonary disease and associated factors: the PLATINO Study in São Paulo, Brazil. Cad Saúde Pública 2005; 21:1565-73.

31. Pearce N, Sunyer J, Cheng S, Chinn S, Björkstén B, Burr M, et al. Comparison of asthma prevalence in the ISAAC and the ECRHS. Eur Respir J 2000; 16:420-6.

Submitted on $21 / \mathrm{Feb} / 2011$

Final version resubmitted on 31/May/2011 Approved on 27/Jun/2011 